PNL-SA-24009

\title{
EVALUATION OF NEW AND CONVENTIONAL THERMOLUMINESCENT PHOSPHORS FOR ENVIRONMENTAL MONITORING USING AUTOMATED THEROLUMINESCENT DOSIMETER READERS
}

\author{
B. A. Rathbone \\ A. W. Endres \\ E. J. Antonio
}

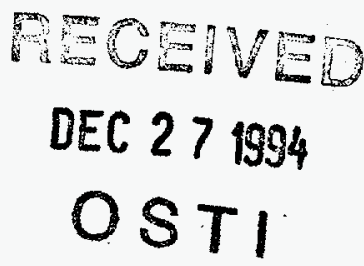

October 1994

Presented at the

Fourth Conference on Radiation Protection and

Dosimetry Conference

October 23-27, 1994

Orlando, Florida

Prepared for

the U.S. Department of Energy

under Contract DE-AC06-76RLO 1830

Pacific Northwest Laboratory

Richland, Washinoton 9935 ?

\section{DISCLAIMER}

This report was prepared as an account of work sponsored by an agency of the United States Government. Neither the United States Government nor any agency thereof, nor any of their employees, makes any warranty, express or implied, or assumes any legal liability or responsibility for the accuracy, completeness, or usefulness of any information, apparatus, product, or process disclosed, or represents that its use would not infringe privately owned rights. Reference herein to any specific commercial product, process, or service by trade name, trademark, manufacturer, or otherwise does not necessarily constitute or imply its endorsement, recommendation, or favoring by the United States Government or any agency thereof. The views and opinions of authors expressed herein do not necessarily state or reflect those of the United States Government or any agency thereof. 


\section{DISCLAIMER}

Portions of this document may be illegible in electronic image products. Images are produced from the best available original document. 


\title{
EVALUATION OF NEW AND CONVENTIONAL THERMOLUMINESCENT PHOSPHORS FOR ENVIRONMENTAL MONITORING USING AUTOMATED THERMOLUMINESCENT DOSIMETER READERS
}

\author{
B. A. Rathbone, A. W. Endres, and E. J. Antonio \\ Pacific Northwest Laboratory, Richland, Washington 99352
}

In recent years, there has been considerable interest in a new generation of super-sensitive thermoluminescent (TL) phosphors for potential use in routine personnel and environmental monitoring (Prokic and Botter-Jensen 1993; Akselrod et al. 1993; Zha et al. 1993; Bacci et a1. 1993; Horowitz 1993). Two of these phosphors, $\alpha-\mathrm{Al}_{2} \mathrm{O}_{3}: \mathrm{C}$ and $\mathrm{LiF}: \mathrm{Mg}, \mathrm{Cu}, \mathrm{P}$, are evaluated in this paper for selected characteristics relevant to environmental monitoring, along with two conventional phosphors widely used in environmental monitoring, $\mathrm{LiF}: \mathrm{Mg}, \mathrm{Ti}$ and $\mathrm{CaF}_{2}:$ Dy. The characteristics evaluated are light-induced fading, 1ightinduced background, linearity and variability at low dose, and the minimum measurable dose. These characteristics were determined using an automated commercial dosimetry system (Harshaw System 8800) and routine processing protocols. Annealing and readout protocols for each phosphor were optimized for use in a large-scale environmental monitoring program.

The use of TL phosphors in the Harshaw system requires mounting of the phosphors on a substrate such as polytetrafluoroethylene (PTFE) or polyimide (e.g., Kapton) film and suspension of the film in a rigid card structure with bar code labe1. The mounting of phosphors in cards poses limits to the oven-annealing and readout temperatures that may be applied. The inability to clear high-temperature traps in LiF:Mg, $\mathrm{Ti}$, in $\mathrm{LiF}: \mathrm{Mg}, \mathrm{Cu}, \mathrm{P}$, and in $\mathrm{CaF}_{2}: \mathrm{Dy}$ can result in significant residual. The inability to clear high-temperature traps in $\alpha-\mathrm{Al}_{2} \mathrm{O}_{3}: \mathrm{C}$ can result in significant 7 ight-induced background in chips with large dose histories (Akselrod et a1. 1993). The manual handling of cards required during loading and unloading of dosimeter holders and the loading and unloading of the reader introduces the potential for contamination and requires some exposure to 1ight. Significant 1ight-induced fading has been reported for $\mathrm{Al}_{2} \mathrm{O}_{3}: C$ (Musk 1993; Mosovitch et al. 1993).

\section{MATERIALS AND METHODS}

A11 thermoluminescent dosimeter (TLD) cards used in this study were manufactured by Bicron for use in the Harshaw Model 8800 TLD reader. The $\alpha-\mathrm{Al}_{2} \mathrm{O}_{3}: \mathrm{C}$ TL phosphor used in these cards is manufactured as single crystal chips by Urals Polytechnical Institute, Ekaterinburg, Russia, and marketed by Bicron under the product name TLD 500. For convenience, this phosphor will be referred to as TLD 500. The LiF:Mg, Cu, P phosphor used in these cards is manufactured as hot-pressed chips by Solid Dosimetric and Method Laboratory, Beijing, Peoples Republic of China, under the product name GR 207 and marketed by Bicron as TLD $700 \mathrm{H}$. For convenience, this phosphore will be referred to as TLD 700H. Both the TLD $700 \mathrm{H}$ phosphor and TLD 700 have a $\mathrm{Li}^{6}$ abundance of $0.007 \%$. The $\mathrm{CaF}_{2}: \mathrm{Dy}$ and $\mathrm{LiF}: \mathrm{Mg}, \mathrm{Ti}$ phosphors used in these cards are manufactured and marketed by Bicron under the product names TLD 200 and TLD 700 , respectively, and will be referred to by these names for convenience. 
The TLD 200 and TLD 700 chips ( $3 \mathrm{~mm} \times 3 \mathrm{~mm} \times 0.9 \mathrm{~mm}$ ) were mounted between two layers of PTFE film to form TL elements on Bicron's standard type 8807 Environmenta7 TLD card, having two TLD 200 and two TLD 700 elements per card. The TLD 500 chips $(5 \mathrm{~mm} \times 0.5 \mathrm{~mm}$ ) were adhesively bonded to Kapton substrate to form $\mathrm{TL}$ elements, with four elements mounted per card. The TLD $700 \mathrm{H}$ chips $(3 \mathrm{~mm} \times 3 \mathrm{~mm} \times 0.5 \mathrm{~mm})$ were also adhesively bonded to Kapton to form TL elements with four elements per card. Thus, the TLD 500 and TLD $700 \mathrm{H}$ phosphor types were represented by their own card types.

The readout equipment used was the Harshaw Model 8800 TLD reader. This is a large-capacity automated reader that uses heated nitrogen gas to heat the chips according to a user-programmable linear time-temperature profile (TTP).

The anneal and readout protocols used for a11 experiments described in this paper were designed to optimize dosimetry performance while maintaining reasonable throughput and handling convenience in a large-scale program. For each phosphor type, the same anneal and readout protocols were used for all experiments. The time-temperature profiles used for each phosphor type are shown in Table 1. For the TLD 200 and TLD 700 chips, separate TTPs were used for annealing and for dosimetric readout. For these phosphors, the anneal procedure consisted of readout under the anneal TTP followed by a 16-hour oven anneal at $80^{\circ} \mathrm{C}$. Oven annealing reduces the traps available for peaks 2 and 3 in TLD 700, thereby improving fade characteristics but has no effect on the TLD 200 chips, which are on the same card. For TLD 500, annealing consisted of one reading using the TTP for dosimetric readout, with no oven anneal. For TLD $700 \mathrm{H}$, annealing consisted of two readings with the dosimetric TTP and no oven anneal. This TTP was chosen after our own studies on sensitivity loss with reuse as a function of maximum readout temperature showed no significant loss of sensitivity with up to 100 readouts at $270^{\circ} \mathrm{C}$. This readout temperature gives a residual of less than $1 \%$, which was considered adequate for environmental dosimetry. These results are in agreement with those of other investigators (Oster et al. 1993).

The TLD 500 and TLD $700 \mathrm{H}$ elements were calibrated using a. ${ }^{90} \mathrm{Sr}$ card irradiator. The TLD 200 and TLD 700 elements were calibrated in air using a ${ }^{60} \mathrm{Co}$ source. The calibration process provides an element correction coefficient (ECC) for each chip that normalizes its sensitivity to the mean sensitivity of the population of calibration chips in the same position. These ECCs were applied to all readings.

For each experiment, the reader was calibrated to provide reader calibration factors (RCFS) for each TTP used. These RCFs were based on the response of calibration cards exposed in the ${ }^{90} \mathrm{Sr}$ card irradiator. This irradiator is calibrated to provide dose in generic units $(\mathrm{gU})$, where one generic unit is approximately equivalent to one millirad or $10 \mu \mathrm{Gy}$. The RCFs based on this irradiator, therefore, have units of $\mathrm{nC} / \mathrm{gU}$. These RCFs were applied by the reader to all card readings. 
TABLE 1. Time-Temperature Profiles

\begin{tabular}{lcccccc}
\hline $\begin{array}{l}\text { TLD Phosphor } \\
\text { Type }\end{array}$ & TLD 200 & $\begin{array}{c}\text { TLD 200 } \\
\text { (anneal) }\end{array}$ & TLD 700 & $\begin{array}{c}\text { TLD 700 } \\
\text { (annea) }\end{array}$ & TLD 500 & TLD 700H \\
\hline $\begin{array}{l}\text { Preheat tempera- } \\
\text { ture }\left({ }^{\circ} \mathrm{C}\right)\end{array}$ & 160 & 50 & 50 & 50 & 50 & 160 \\
$\begin{array}{l}\text { Preheat time } \\
\text { (sec) }\end{array}$ & 25 & 0 & 0 & 0 & 0 & 5 \\
$\begin{array}{l}\text { Temperature rate } \\
\left({ }^{\circ} \mathrm{C} / \mathrm{sec}\right)\end{array}$ & 20 & 20 & 10 & 10 & 5 & 20 \\
$\begin{array}{l}\text { Maximum tempera- } \\
\text { ture }\left({ }^{\circ} \mathrm{C}\right)\end{array}$ & 300 & 300 & 300 & 300 & 300 & 270 \\
$\begin{array}{l}\text { Acquire time } \\
(\mathrm{sec})\end{array}$ & 20 & 40 & 33.3 & 33.3 & 60 & 16.6 \\
$\begin{array}{l}\text { Anneal tempera- } \\
\text { ture }\left({ }^{\circ} \mathrm{C}\right)\end{array}$ & 0 & 0 & 0 & 300 & 0 & 0 \\
$\begin{array}{l}\text { Anneal time } \\
\text { (sec) }\end{array}$ & 0 & 0 & 0 & 6 & 0 & 0 \\
\hline
\end{tabular}

\section{Light-Induced Fading}

White, yellow, and red lighting environments were constructed in the laboratory to produce uniform lighting at a level of 300 lux on designated work surfaces. The white lighting was provided by standard 40-watt warm white fluorescent tubes; the yellow lighting was provided by General Electric F40G0 gold fluorescent tubes; the red lighting was provided by incandescent red bulbs. A1l lighting was filtered by transparent ultraviolet (UV) blocking film. Cards containing each chip type were annealed, then exposed to $100 \mathrm{gU}$ (1 mGy) using a ${ }^{90} \mathrm{Sr}$ card irradiator. Ten cards of each type were exposed for durations of $1,3,10,30,100$, and 300 minutes to the warm white source. Ten cards of each type were also exposed to the yellow and red light for the same durations. The same day, cards of each type were read together along with a set of controls of each card type exposed to the ${ }^{90} \mathrm{Sr}$ source but not to 1 ight.

\section{Light-Induced Background}

Groups of 10 TLD 500 cards were annealed, then exposed to red, yellow, and warm white light at an illumination level of 300 lux for durations of $1,3,10,30,100$, and 300 minutes and read the same day with unexposed controls. To the author's knowledge, each of these chips had a cumulative radiation dose history of 1 Gy or less before performing this experiment. Throughout each of these 1ight experiments, great care was taken to avoid unnecessary exposure to light. 


\section{Linearity and Variability at Low Dose}

After annealing, cards of each type were loaded into Harshaw 8807 Environmental Dosimeter holders to minimize exposure to light. The holders used for the TLD 500 cards and for the TLD $700 \mathrm{H}$ cards provided $80 \mathrm{mg} / \mathrm{cm}^{2}$ of ABS plastic filtration. The holders used for the 8807 card (TLD 200 and TLD 700) provided $422 \mathrm{mg} / \mathrm{cm}^{2} \mathrm{Ta}+58 \mathrm{mg} / \mathrm{cm}^{2} \mathrm{~Pb}$ filtration over front and back sides of the TLD 200 elements in addition to the $80 \mathrm{mg} / \mathrm{cm}^{2}$ ABS over all elements. Groups containing 10 dosimeters of each type (8807, TLD 500, TLD 700H) were exposed to $0.1,0.3,1.0,3.0,10.0,30.0$, and $100.0 \mathrm{mR}$ in air from a ${ }^{137} \mathrm{Cs}$ source. The estimated error in the applied exposure in all cases was less than 5\%. A group containing 10 dosimeters of each type was designated as a control and accompanied the experimental dosimeters to and from the irradiation facility. Card annealing was performed the day before irradiations and readout was conducted on the same day as the irradiations.

\section{Minimum Measurable Dose}

The standard deviation of control dosimeters in the linearity test was used to calculate the minimum measurable dose for each phosphor type.

\section{RESULTS AND DISCUSSION}

\section{Light-Induced Fading}

The results of the light-induced fading experiments are summarized in Table 2. All readings were obtained with ECC and RCF (nC/gU) applied. To obtain the fade factor, the mean result for each chip position in an exposure group was normalized to the mean of exposed control chips in the same position. The fade factors for all chip positions were averaged to obtain the single fade factor shown in Table 2. Thus, for TLD 500 and TLD 700H, the fade factor was based on 40 data points per exposure condition. For TLD 200 and TLD 700, the average was based on 20 chips per exposure condition. The relative standard deviation was calculated for each chip position and the average reported in Table 2. In general, the results were as expected. The only phosphor to show significant fading was the TLD 500. The data for this phosphor are plotted in Figure 1. Other investigators have reported strong light-induced fading in TLD 500 for white and yellow light. It is interesting to note the superior performance of red lighting at the same level of 111 umination as the other sources. Other investigators have reported significant UV light-induced fading in TLD 200. The fact that none was observed in the present experiments attests to the effectiveness of the UV filter employed. Minimal sensitivity to visible light has been reported in the literature for both TLD 700 and TLD $700 \mathrm{H}$, which is consistent with the data in Table 2. 
TABLE 2. Light-Induced Fading

\begin{tabular}{|c|c|c|c|c|c|c|}
\hline \multirow[t]{2}{*}{ Time, min } & \multicolumn{2}{|c|}{ Red } & \multicolumn{2}{|c|}{ Yellow } & \multicolumn{2}{|c|}{ White } \\
\hline & Avg & $\%$ Std & Avg & $\%$ Std & Avg & $\%$ Std \\
\hline \multicolumn{7}{|c|}{ TLD 200} \\
\hline $\begin{array}{r}1 \\
3 \\
10 \\
30 \\
100 \\
300 \\
\end{array}$ & $\begin{array}{l}0.99 \\
0.99 \\
1.01 \\
0.99 \\
1.00 \\
1.00 \\
\end{array}$ & $\begin{array}{l}2.8 \\
1.9 \\
2.3 \\
3.2 \\
1.1 \\
1.9 \\
\end{array}$ & $\begin{array}{l}1.00 \\
1.01 \\
1.00 \\
0.99 \\
1.01 \\
1.00 \\
\end{array}$ & $\begin{array}{l}2.7 \\
3.5 \\
2.2 \\
2.0 \\
2.2 \\
2.1 \\
\end{array}$ & $\begin{array}{l}1.00 \\
0.99 \\
1.00 \\
0.98 \\
1.00 \\
1.01 \\
\end{array}$ & $\begin{array}{l}2.5 \\
1.5 \\
2.0 \\
2.5 \\
1.6 \\
1.3 \\
\end{array}$ \\
\hline \multicolumn{7}{|c|}{ TLD 700} \\
\hline $\begin{array}{r}1 \\
3 \\
10 \\
30 \\
100 \\
300 \\
\end{array}$ & $\begin{array}{l}1.00 \\
0.99 \\
1.00 \\
0.99 \\
1.00 \\
1.00\end{array}$ & $\begin{array}{l}1.2 \\
1.0 \\
1.0 \\
1.4 \\
1.3 \\
0.9\end{array}$ & $\begin{array}{l}1.00 \\
1.00 \\
1.00 \\
1.00 \\
1.00 \\
1.03 \\
\end{array}$ & $\begin{array}{l}1.3 \\
1.1 \\
0.6 \\
1.2 \\
2.3 \\
2.3 \\
\end{array}$ & $\begin{array}{l}0.99 \\
1.00 \\
0.99 \\
1.00 \\
1.00 \\
1.01 \\
\end{array}$ & $\begin{array}{l}1.3 \\
1.4 \\
1.8 \\
1.6 \\
1.7 \\
1.7 \\
\end{array}$ \\
\hline \multicolumn{7}{|c|}{ TLD 500} \\
\hline $\begin{array}{r}1 \\
3 \\
10 \\
30 \\
100 \\
300 \\
\end{array}$ & $\begin{array}{l}1.01 \\
1.00 \\
1.00 \\
0.99 \\
0.93 \\
0.80 \\
\end{array}$ & $\begin{array}{l}0.6 \\
0.4 \\
0.5 \\
0.8 \\
1.7 \\
5.1 \\
\end{array}$ & $\begin{array}{l}1.00 \\
1.00 \\
0.98 \\
0.94 \\
0.82 \\
0.58 \\
\end{array}$ & $\begin{array}{r}0.6 \\
0.5 \\
0.5 \\
1.4 \\
4.0 \\
12.1 \\
\end{array}$ & $\begin{array}{l}1.00 \\
1.00 \\
0.97 \\
0.91 \\
0.73 \\
0.42 \\
\end{array}$ & $\begin{array}{r}0.6 \\
1.5 \\
0.9 \\
2.6 \\
6.2 \\
25.6 \\
\end{array}$ \\
\hline \multicolumn{7}{|c|}{ TLD $700 \mathrm{H}$} \\
\hline $\begin{array}{r}1 \\
3 \\
10 \\
30 \\
100 \\
300\end{array}$ & $\begin{array}{l}0.99 \\
0.98 \\
0.98 \\
0.99 \\
0.99 \\
1.00\end{array}$ & $\begin{array}{l}1.3 \\
2.0 \\
1.9 \\
1.8 \\
1.9 \\
2.4\end{array}$ & $\begin{array}{l}1.01 \\
0.99 \\
0.99 \\
0.99 \\
0.97 \\
0.96\end{array}$ & $\begin{array}{l}1.3 \\
2.4 \\
2.4 \\
2.0 \\
2.6 \\
2.0\end{array}$ & $\begin{array}{l}0.98 \\
0.98 \\
0.98 \\
0.99 \\
0.99 \\
0.98\end{array}$ & $\begin{array}{l}1.8 \\
2.8 \\
1.7 \\
2.3 \\
2.9 \\
1.3\end{array}$ \\
\hline
\end{tabular}




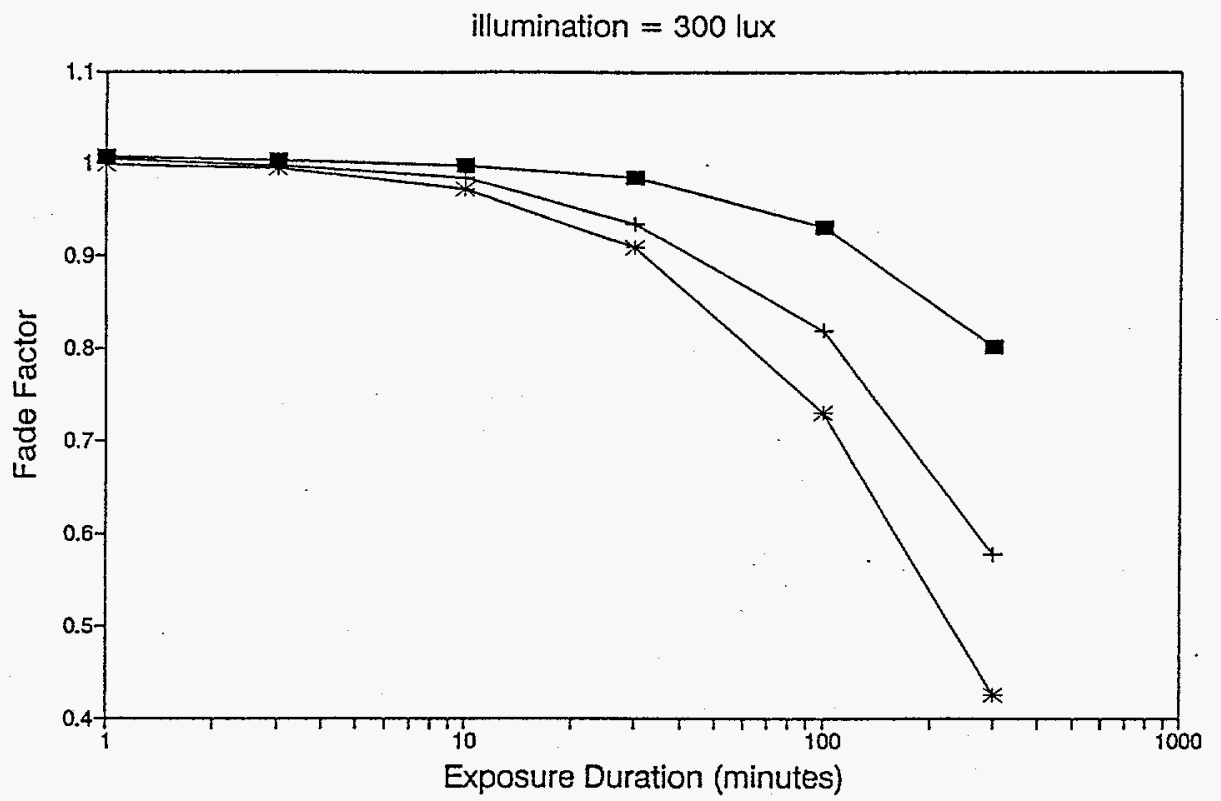

FIGURE 1. Led + Yellow - L-Warm White
Light-Induced Fading in TLD 500

\section{Light-Induced Background}

The cards were read on a reader previously calibrated with cards exposed to $100 \mathrm{gU}$ with the ${ }^{90} \mathrm{Sr}$ card irradiator. The ECCs and RCFs were applied to all chip readings. For each exposure group (five cards) the mean and standard deviation for each chip position were calculated and the results averaged to obtain a single mean and standard deviation value for the group. The results are shown in Table 3 and Figure 2. Even though the cards had a prior dose history of less than $0.01 \mathrm{~Gy}$, a small background effect is evident. It is believed that the 1 ight-induced background in TLD 500 results from 1 ighttransferred sensitivity from higher temperature traps and that the background effect will be greater with larger cumulative doses on the chip.

TABLE 3. Light-Induced Background at 300 lux, $\mu$ Gy

\begin{tabular}{|c|c|c|c|c|c|c|}
\hline \multirow{2}{*}{$\begin{array}{c}\text { Exposure, } \\
\text { min }\end{array}$} & \multicolumn{2}{|c|}{ Red } & \multicolumn{2}{|c|}{ Yellow } & \multicolumn{2}{|c|}{ White } \\
\hline & Avg & $\%$ Std & Avg & $\%$ Std & Avg & $\%$ Std \\
\hline $\begin{array}{r}0 \\
1 \\
3 \\
10 \\
30 \\
100 \\
300\end{array}$ & $\begin{array}{l}2.90 \\
3.24 \\
3.17 \\
3.20 \\
2.94 \\
3.27 \\
3.43\end{array}$ & $\begin{array}{l}0.27 \\
0.29 \\
0.53 \\
0.32 \\
0.38 \\
0.38 \\
0.33\end{array}$ & $\begin{array}{l}2.90 \\
2.90 \\
3.00 \\
3.04 \\
3.05 \\
3.28 \\
3.78\end{array}$ & $\begin{array}{l}0.27 \\
0.19 \\
0.27 \\
0.43 \\
0.38 \\
0.43 \\
0.64\end{array}$ & $\begin{array}{l}2.90 \\
3.09 \\
3.07 \\
3.78 \\
4.48 \\
5.50 \\
9.25\end{array}$ & $\begin{array}{l}0.27 \\
0.36 \\
0.28 \\
0.86 \\
1.38 \\
2.13 \\
4.27\end{array}$ \\
\hline
\end{tabular}




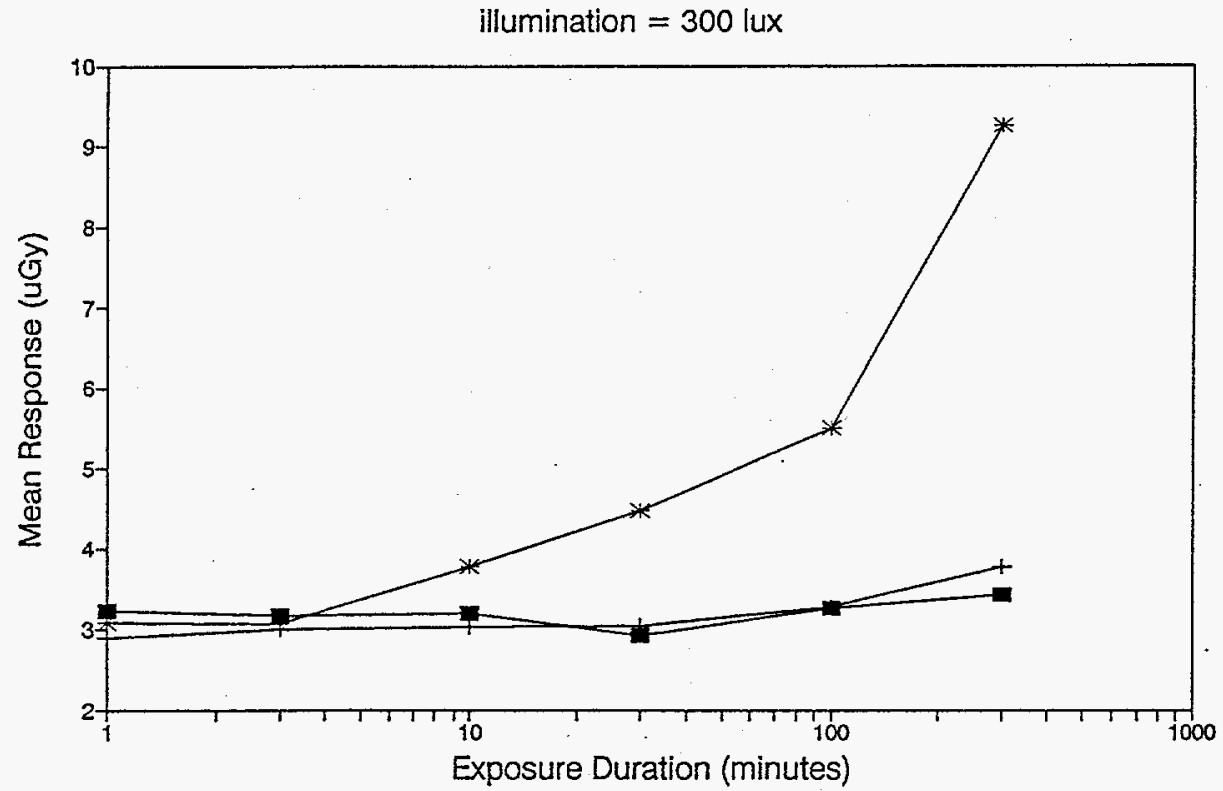

- Red T Yellow $\quad$ * Warm White

FIGURE 2. Light-Induced Background in TLD 500

\section{Linearity and Variability at Low Dose}

Cards were read on a reader calibrated using the ${ }^{90} \mathrm{Sr}$ irradiator, and ECCs and RCFs were applied to all chip readings by the reader. For each chip type, the zero dose reading from the set of control dosimeters was subtracted from the reading of each experimental dosimeter and the net reading adjusted by a one-point calibration factor $(\mathrm{gU} / \mathrm{mR})$ derived from the response of the dosimeters exposed to $100 \mathrm{mR}$. For each group, the mean and standard deviation of these net adjusted readings were calculated from all chips in an exposure group without regard to chip position to obtain a single value for the exposure level and chip types. The results are shown in Tables 4 and 5 . Linear regression analysis was performed on the mean adjusted readings in Table 4; the results are shown in Table 6 . These results show excellent linearity for all phosphor types. The relative standard deviation in percent as a function of exposure is plotted in Figure 3. The standard deviation values in Table 5 and Figure 3 are for net responses. It should be noted that the TLD 500 and TLD $700 \mathrm{H}$ chips were calibrated using a ${ }^{90} \mathrm{Sr}$ card irradiator having close geometry. Because of the field gradient, and the nonpenetrating nature of beta radiation, small variations in chip positioning and chip thickness on the card can result in measurable random error in the ECC. This error is evident in the fact that the standard deviation for TLD 500 is on the order of $0.5 \%$ (Table 2) when irradiated with the ${ }^{90} \mathrm{Sr}$ irradiator used for ECC generation. The true variability for TLD 500 at exposures above $1 \mathrm{mR}$ is probably less than $1 \%$. 
TABLE 4. Mean Adjusted Readings

\begin{tabular}{crrrr}
\hline Exposure Leve1, mR & TLD 200 & TLD 700 & TLD 500 & \multicolumn{1}{c}{ TLD 700H } \\
\hline 0.1 & 0.099 & 0.096 & 0.105 & 0.100 \\
0.3 & 0.289 & 0.246 & 0.299 & 0.298 \\
1.0 & 0.975 & 1.002 & 1.004 & 1.005 \\
3.0 & 2.957 & 2.972 & 2.997 & 2.943 \\
10.0 & 9.879 & 9.979 & 9.978 & 10.032 \\
30.0 & 29.929 & 30.031 & 29.894 & 30.464 \\
100.0 & 100.000 & 100.000 & 100.000 & 100.000 \\
\hline
\end{tabular}

TABLE 5. Percent Coefficient of Variation for Adjusted Readings

\begin{tabular}{crrrr}
\hline Exposure Leve1, mR & TLD 200 & TLD 700 & TLD 500 & \multicolumn{1}{c}{ TLD 700H } \\
\hline 0.1 & 17.801 & 307.348 & 20.622 & 111.102 \\
0.3 & 6.110 & 33.337 & 6.659 & 37.820 \\
1.0 & 1.968 & 16,983 & 3.202 & 16.962 \\
3.0 & 2.336 & 5.477 & 2.678 & 4.328 \\
10.0 & 2.025 & 1.371 & 2.055 & 3.148 \\
30.0 & 1.510 & 0.927 & 1.754 & 2.576 \\
100.0 & 0.605 & 1.274 & 1.104 & 2.008 \\
\hline
\end{tabular}

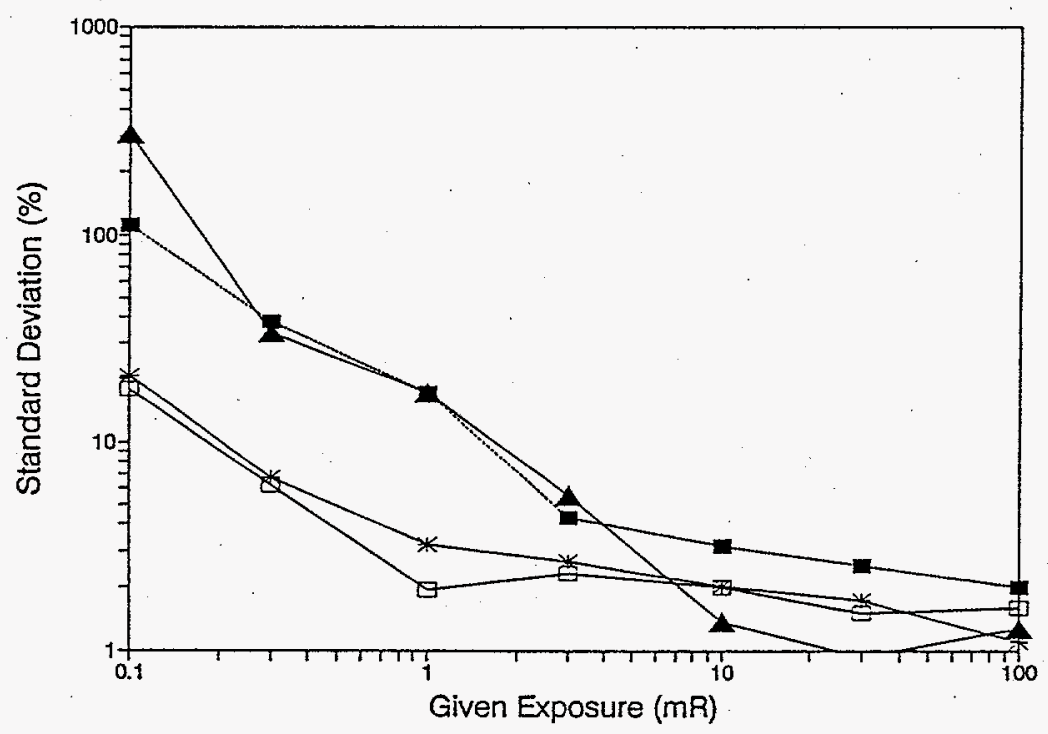

A- TL $700 \rightarrow$ TLD $700 \mathrm{H} *$ TL 500 TLO 200

FIGURE 3. Variability at Low Dose for TLD 200, TLD 500, 
TABLE 6. Phosphor Regression Data

\begin{tabular}{llccc}
\hline & TLD 200 & TLD 500 & TLD 700 & TLD 700H \\
\hline Constant & -0.04468 & -0.01515 & -0.01586 & 0.050512 \\
$\begin{array}{l}\text { Standard Error of } \\
\text { Y Est. }\end{array}$ & 0.047256 & 0.043896 & 0.027233 & 0.194348 \\
$\mathrm{R}^{2}$ & 0.999999 & 0.999999 & 1 & 0.999977 \\
$\begin{array}{l}\text { Number of } \\
\text { Observations }\end{array}$ & 7 & 7 & 7 & 7 \\
$\begin{array}{l}\text { Degrees of Freedom } \\
\text { X Coefficients }\end{array}$ & 5 & 5 & 5 & 5 \\
$\begin{array}{l}\text { Standard Error of } \\
\text { Coefficient }\end{array}$ & 0.000527 & 0.00049 & 0.000304 & 0.002169 \\
\hline
\end{tabular}

\section{Minimum Measurable Dose}

The standard deviation of unexposed control dosimeter readings expressed in $\mathrm{mR}$ was used to calculate the minimum measurable dose (MMD) for each phosphor type. Using the relationship MMD $=3 \sigma_{B}$, where $\sigma_{B}$ is the standard deviation of the zero dose reading, the MMDs were calculated for Table 7. For the anneal and readout protocols used, the sensitivity of each phosphor relative to $15-\mathrm{mi} 1$ TLD $700(3 \mathrm{~mm} \times 3 \mathrm{~mm} \times 0.4 \mathrm{~mm})$ is shown in Table 7 . These sensitivities are based on the phosphor response to ${ }^{137} \mathrm{CS}$ gamma radiation.

\section{TABLE 7. Sensitivity and Minimum Dose}

\begin{tabular}{ccccc}
\hline Phosphor Type & $\begin{array}{c}\text { Dimensions, } \\
\mathrm{mm}\end{array}$ & $\begin{array}{c}\text { Reader } \\
\text { Calibration } \\
\text { Factor, nC/mR }\end{array}$ & $\begin{array}{c}\text { Relative } \\
\text { Sensitivity }\end{array}$ & $\begin{array}{c}\text { Minimum } \\
\text { Measurable } \\
\text { Dose }\end{array}$ \\
\hline TLD 200 & $3 \times 3 \times 0.9$ & 8.0 & 40 & 0.051 \\
TLD 700 & $3 \times 3 \times 0.9$ & 0.45 & 2.25 & 0.645 \\
TLD 700 & $5 \times 0.5$ & 9.8 & 50 & 0.063 \\
TLD 700H & $3 \times 3 \times 0.5$ & 1.5 & 7.5 & 0.306 \\
\hline
\end{tabular}

\section{CONCLUSIONS}

A11 phosphors exhibited excellent linearity down to $0.1 \mathrm{mR}$. A11 phosphors exhibited good reproducibility above $10 \mathrm{mR}$ while TLD 200 and TLD 500 appear to be better choices for exposures below 10 mR (monthly or weekiy monitoring). Only TLD 500 showed significant 1ight-induced background or fading under laboratory lighting. Special lighting and handling will be necessary for use of this phosphor in a routine program. Yellow and red 
lighting appear to offer adequate handling time for loading and unloading of dosimeter holders and TLD readers with the TLD 500 card.

\section{ACKNOWLEDGMENTS}

Pacific Northwest Laboratory is operated for the U.S. Department of Energy by Battelle Memorial Institute under Contract DE-AC06-76RL0 1830.

\section{REFERENCES}

Akselrod, M. S., V. S. Kortov, and E. A. Gorelova. 1993. "Preparation and Properties of $\alpha-\mathrm{Al}_{2} \mathrm{O}_{3}: \mathrm{C}$." Radiation Protection Dosimetry 47(1-4):159-164.

Bacci, C., L. D'Ange70, C. Furetta, and S. Giancola. 1993. "Comprehensive Study on LiF:CU,Mg,P (GR-200 A)." Radiation Protection Dosimetry $47(1-4): 215-218$.

Horowitz, Y. S. 1993. "LiF:Mg,Ti Versus LiF:Mg, Cu,P: The Competition Heats Up." Radiation Protection Dosimetry 47(1-4):135-141.

Moscovitch, M., R. A. Tawil, and M. Svinkin. 1993. "Light Induced Fading in $\alpha-\mathrm{Al}_{2} \mathrm{O}_{3}:$ C." Radiation Protection Dosimetry 47(1-4):251-253.

Musk, J. H. 1993. "Time Dependent and Light-Induced Fading in Victoreen Mode1 2600-80 Aluminum 0xide Thermoluminescence Dosemeters." Radiation Protection Dosimetry $47(1-4): 247-249$.

Oster, L., Y. S. Horowitz, and A. Horowitz. 1993. "Glow Curve Readout of $\mathrm{LiF}: \mathrm{Mg}, \mathrm{Cu}, \mathrm{P}(\mathrm{GR}-200)$ Chips at Maximum Temperatures Between $240^{\circ} \mathrm{C}$ and $280^{\circ} \mathrm{C}$ : Elimination of the Residual Signal." Radiation Protection Dosimetry $49(4): 407-411$.

Prokic, M., and L. Botter-Jensen. 1993. "Comparison of Main Thermoluminescent Properties of Some TL Dosemeters." Radiation Protection Dosimetry 47(1-4):195-199.

Zha, Z., S. Wang, W. Shen, J. Zhu, and G. Cai. 1993. "Preparation and Characteristics of LiF:Mg, Cu,P Thermoluminescent Material." Radiation Protection Dosimetry 47(1-4):111-118. 